\title{
Early Endothelial Progenitor Cells (eEPCs) in systemic sclerosis (SSC) - dynamics of cellular regeneration and mesenchymal transdifferentiation
}

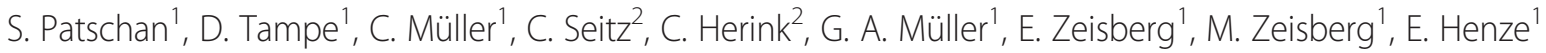
and D. Patschan ${ }^{1 *}$

\begin{abstract}
Background: Patients with systemic sclerosis (SSc) are endagered by tissue fibrosis and by microvasculopathy, with the latter caused by endothelial cell expansion/proliferation. SSc-associated fibrosis potentially results from mesenchymal transdifferentiation of endothelial cells. Early Endothelial Progenitor Cells (eEPCs) act proangiogenic under diverse conditions. Aim of the study was to analyze eEPC regeneration and mesenchymal transdifferentiation in patients with limited and diffuse SSs (ISSC and dSSC).

Methods: Patients with both, ISSc and dSSc were included into the study. The following parameters were evaluated: eEPC numbers and regeneration, concentrations of vasomodulatory mediators, mesenchymal properties of blood-derived eEPC. Serum samples of healthy subjects and SS patients were used for stimulation of cultured human eEPC, subsequently followed by analysis of mesenchymal cell characteristics and mobility.

Results: Twenty-nine patients were included into the study. Regenerative activity of blood-derived eEPCs did not differ between Controls and patients. Circulating eEPC were significantly lower in all patients with SSC, and in limited and diffuse SSc (ISSc/dSSc). Serum concentrations of promesenchymal TGF-b was elevated in all patients with SSc. Cultured mononuclear cells from SS patients displayed higher abundances of CD31 and of CD31 and aSMA combined. Finally, serum from SSC patients inhibited migration of cultured eEPCs and the cells showed lower sensitivity towards the endothelin antagonist Bosentan.

Conclusions: The eEPC system, which represents an essential element of the endogenous vascular repair machinery is affected in SSc. The increased appearance of mesenchymal properties in EEPC may indicate that alterations of the cells potentially contribute to the accumulation of connective tissue and to vascular malfunction.
\end{abstract}

\section{Background}

Systemic Sclerosis (SSc) is characterized by severe microvasculopathy, causing ongoing hypoperfusion of skin and inner organs [1]. Pathological analysis reveals endothelial cell proliferation in small blood vessels, subsequently leading to vascular obstruction ('onion skin lesions') [2]. Another hallmark in SSc is the

\footnotetext{
* Correspondence: d.patschan@gmail.com

${ }^{1}$ Clinic of Nephrology and Rheumatology, University Hospital of Göttingen,

Robert-Koch-Straße 40, 37075 Göttingen, Germany

Full list of author information is available at the end of the article
}

accumulation of collagen fibers in skin, lungs, heart, and intestine. Such fibrosis or sclerosis can dramatically affect the functional integrity of organs/the whole organism [3]. The etiopathogenesis of the disease is far from being understood and although therapeutic measures are often intended to modulate the immune response in order to inhibit vasculopathy and fibrogenesis, the prognosis of SSc patients is quite poor since the course of the disease remains unaffected by drug therapy in many cases [4]. Thus, it can at least be doubted whether the cellular and molecular processes, responsible for 
endothelial cell proliferation and collagen accumulation are exclusively autoimmune by nature.

The field of vascular biology has significantly been emerged in recent years. This is particularly the case with regard to vascular repair mechanisms. In 1997, Asahara and colleagues described a population of bloodderived cells, critically involved in neovascularization [5]. These cells, termed Endothelial Progenitor Cells (EPCs) are heterogenous in terms of origin and phenotype [6-8]. They can promote post-ischemic vascular regeneration by both, direct and indirect mechanisms. Early Endothelial Progenitor Cells (eEPC) represent one major subpopulation of EPCs and they have meanwhile been used for therapeutic purposes in different experimental situations and in humans suffering from ischemic diseases [9-13]. Several recent investigations evaluated numbers of circulating eEPC in SSc [14-16]. However, in none of the studies, regenerative activity of eEPC was analyzed in SSc. We therefore aimed to quantify eEPC regeneration in SSc and utilized a Colony-Forming Unit Assay as described and reviewed previously [11, 17-19]. Our particular interest focused on phenotypic characteristics, possibly associated with a pro-mesenchymal switch of the cells within the (peri)vascular microenvironment.

\section{Methods}

\section{Design and patients}

The present investigation was a prospective singlecenter analysis. All patients were treated at the department of nephrology and rheumatology (University Hospital of Göttingen, Germany) between 2011 and 2013. All included individuals were classified according to the 2013 ACR(American College of Rheumatology)/ EULAR(European League Against Rheumatism) criteria [20]. Differentiation between limited and diffuse SSc was made in accordance with the criteria published by LeRoy and Medsger [21]. The term 'diffuse (generalized) disease' is intended to describe patients with skin involvement, extended even to proximal areas of arms and legs including possible manifestations at the trunk (thorax and abdomen). These patients suffer more often and, if present, in many cases from more serious organ involvement. However, patients with limited disease may also show organic manifestations such as interstitial lung disease and esophageal damage. Lung involvement was defined as a lower than normal diffusion capacity (below $80 \%$ of the nominal value) and/or as interstitial lung affection in radiographic analysis (chest $\mathrm{x}$-ray or CT (Computed Tomography) scan) and/or as pulmonary hypertension. The latter was diagnosed by transthoracic echocardiogram. Esophageal manifestation was defined as either persistent dysphagea and/or as pathological esophagram. Joint affection was defined clinically if patients suffered from arthralgia. Renal involvement was defined by either increased serum creatinine and/or by proteinuria of above $150 \mathrm{mg} /$ day. The patients underwent variable treatment regimens including administration of immunosuppressants for different reasons. For further clinical characterization a number of different parameters, such as c-reactive protein and different autoantibodies including anti-Scl70 and anti-Centromer were measured and collected in the database of the Clinic of Nephrology \& Rheumatology (University Hospital of Göttingen, Germany). The control subjects $(n=16)$ matched the patients in terms of gender and age. They also signed written consent. Individuals in the control group were recruited from the staff of the University Hospital of Göttingen.

\section{eEPC quantification and regeneration}

Quantification of peripheral circulating eEPC and analysis of eEPC regeneration was performed as described in numerous previous studies [11, 13, 18, 19, 22]. Nevertheless, in order to supply a better understanding of the parameters used for detecting eEPCs from the blood and for evaluating eEPC regeneration, the methodical approaches shall be outlined more in detail. Quantification of peripheral circulating eEPCs was performed by flow cytometry. Mononuclear cells (MNCs) were isolated by density gradient centrifugation using Histopaque-1077 solution (Sigma Diagnostics, St. Louis, MO) from $\approx 7.5 \mathrm{ml}$ of heparinized peripheral blood. Cells were initially incubated for $1 \mathrm{~h}$ (on ice) using the following antibodies: rabbit anti CD133 (ab16518 - Abcam, Cambridge, UK), mouse anti human VEGFR2 (Vacular Endothelial Growth Factor Receptor 2 - KDR, directly conjugated - FAB $3571 \mathrm{~F}$ R\&D Systems, Minneapolis, MN, USA), followed by secondary incubation with PE-conjugated goat anti rabbit Fab (VEGFR, 111-116-144 - Jackson Immunoresearch, Baltimore, PA, USA) for $30 \mathrm{~min}$ on ice, respectively. After incubation, cells were washed with PBS-BSA $1 \%(\mathrm{w} / \mathrm{v})$. Data were acquired using a FACScalibur cytometer (Becton Dickinson, Heidelberg, Germany) equipped with a $488 \mathrm{~nm}$ argon laser and a $635 \mathrm{~nm}$ red diode laser and analyzed using CellQuest software (Becton Dickinson, San Jose, CA, USA). The setup of FACScalibur was performed according to the manufacturer's instructions using unstained and single-antibody stained cells. Specificity of staining was controlled by incubation with isotype-matched immunoglobulins. To quantify eEPCs, the numbers of CD133/KDR doublepositive cells within the myelomonocytic cell population were counted. eEPC regeneration on the other hand was evaluated by a Colony-Forming Units (CFU) assay. The assay was performed by using the EndoCult Liquid Medium Kit ${ }^{\bullet}$ (StemCell Technologies, Vancouver, BC, Canada) per the manufacturer's protocol. MNCs were resuspended in complete EndoCult medium and seeded at 
$5 \times 10^{6}$ cells/well on fibronectin-coated tissue culture plates (BD Biosciences, Rockville, MD, USA). After 48 h, wells were washed with media and nonadherent cells were collected. Nonadherent cells were plated in their existing media at $10^{6}$ cells/well in 24 well fibronectin-coated tissue culture plates for three days. Only colonies with at least 20 cells, containing rounded cells in the middle and elongated cells at the periphery, were considered as CFU-EC (Colony Forming Unit-Endothelial Cell) colonies. The numbers of colonies (colonies/well) appearing after this period were counted. At least two members of the laboratory staff evaluated the numbers. They were blinded for the diagnosis and status of the investigated patients/controls. The phenotype of cells within the colonies was determined more in detail. For this purpose, cells were characterized by the uptake of DiI-labeled acetylated low density lipoprotein (Dil-acLDL) (Invitrogen, Carlsbad, CA, USA) and binding of FITC-labeled UE lectin (Sigma Diagnostics, St. Louis, MO). Cells were first incubated with $10 \mu \mathrm{g} / \mathrm{ml}$ DiI-ac-LDL at $37{ }^{\circ} \mathrm{C}$ for $1 \mathrm{~h}$ and later fixed with $2 \%$ formaldehyde for $10 \mathrm{~min}$, followed by incubation with UE(Ulex Europaeus) lectin at $37{ }^{\circ} \mathrm{C}$ for $1 \mathrm{~h}$. In some experiments, cells were additionally stained for FSP-1 (see below). The number and of Dil-acLDL+/UE lectin +/ FSP$1+$ cells was counted by laser scanning microscopy using an inverted fluorescence microscope IX-71 (Olympus Deutschland GmbH, Hamburg, Germany) equipped with the appropriate excitation and emission filters (AHF Analysentechnik, Tübingen, Germany). In order to provide some information about concistency of the CFU-EC assay, we compared the cumulative mean colony numbers aquired from healthy controls evaluated in three different studies from the past $[19,22]$. One of the three studies has not been published yet. The mean number of colonies in all studies was $29.9 \pm 2.2$. It did not significantly differ from the current mean in healthy controls $(p=0.15)$.

\section{Mesenchymal transdifferentiation analysis}

For mesenchymal transdifferentiation analysis mononuclear cells, isolated by density gradient centrifugation using Histopaque-1077 solution (Sigma Diagnostics, St. Louis, $\mathrm{MO}$ ) were seeded on fibronectin-coated dishes in EGM-2 medium (Endothelial cell medium-2, Clonetics, Lonza, Walkersville, MD, USA) at $5 \times 10^{6}$ cells/well. After two days, non-adherent cells were removed and adherent cells were cultured for five further days in EGM-2. Cells were washed with PBS/BSA $1 \%$ and primary incubation was performed with the following antibodies: Mouse Anti-Human CD31 (DAKO, M0823), Rabbit Anti-Human aSMA (alpha Smooth Muscle Actin) (Abcam, ab32575), or Rabbit Anti-Human FSP-1 (Fibroblast Specific Protein-1) (DAKO, A5114). Incubation was done for $12 \mathrm{~h}$ at $4{ }^{\circ} \mathrm{C}$ overnight in a humidified chamber. After washing the cells once with PBS/BSA
$1 \%$, secondary incubation was performed for $1 \mathrm{~h}$ at room temperature using the following antibodies: Alexa Fluor 488 donkey anti-mouse or Alexa Fluor 555 donkey anti-rabbit. After additional washing steps cells were coated with DAPI containing Vectashield Mounting Medium (Sigma-Aldrich, Taufkirchen, Germany). The percentages of $\mathrm{CD} 31+$, and of $\mathrm{CD} 31+/ \mathrm{aSMA}+$, cells were counted by laser scanning microscopy using the same microscope as described above (inverted fluorescence microscope IX-71 - Olympus Deutschland GmbH, Hamburg, Germany). Results were given as percentages of double-positive cells per nuclei.

\section{Elisa studies}

Measurements of serum Angiopoietin-1 and -2, VEGF, TGF-beta (Transforming Growth Factor-beta), and PDGF (Platelet Derived Growth Factor) were performed using commercially available kits (all from R\&D, Wiesbaden, Germany) according to the manufacturer's protocol.

\section{Serum stimulation of cultured eEPC and eEPC migration assay}

For serum stimulation and cell migration experiments, a commercially available human EPC cell line was employed (Human CD133+ Endothelial Progenitor Cells, BioChain, CA, USA). Cells were seeded after the 4th passage on gelatine-coated 24-well plates. The migration assay was performed as described previously (18). In detail, an artificial wound was created after the cells completely covered the dish in a homogenous manner. A standardized stamp was used for wound induction, allowing to create comparable wound areas. Shortly before wound induction, the incubation procedure was initiated. Serum samples from either healthy subjects or from SSc patients were diluted in EGM-2 (serum:medium-ratio $=1: 5$ or 1:7.5) and $600 \mu \mathrm{l}$ were administered to the cells for $8 \mathrm{~h}$ in total. In some experiments Bosentan was additionally applied at 2000 or at $1000 \mathrm{ng} / \mathrm{ml}$ for the same period. At the beginning and $5 \mathrm{~h}$ after the end of the incubation procedure, wound areas were quantified. For analysis of EndoMT, cells were directly grown on glass bottom slides which allowed a more detailed microscopic investigation. The cell treatment protocol was the same. The staining procedure for endothelial (CD31) and mesenchymal markers (aSMA) and the subsequent analyses were performed as described earlier (see Mesenchymal transdifferentiation analysis).

\section{Statistical analysis}

The results were expressed as mean \pm SEM. The means of two populations were compared by Student's $t$ test. Three or more groups were compared by two-way ANOVA. Differences were considered significant at $p<0.05$. 


\section{Results}

\section{Patients}

A total number of 29 patients with systemic sclerosis was included into the study. The limited form was diagnosed in 21 (female: 19, male: 2), the diffuse type in eight patients (female: six, male: two). The mean age of all patients was $56 \pm 2.5$ years with $58 \pm 2.5$ years in patients with limited and $50 \pm 5.7$ years in patients with generalized SS. The mean duration of the disease was $4.5 \pm$ 0.8 years in all patients with $4.6 \pm 0.9$ years in limited and $4.2 \pm 1.5$ years in diffuse SSc. The respective autoantibody profiles are shown in Additional file 1: Table S1. Pulmonary involvement was diagnosed in one patient with ISSc (4.7\%) and in two patients with dSSc (25\%). Other organ manifestations were: esophagus - 1SSc $28 \%(n=6)$, dSSc $37.5 \%(n=3)$, joints - 1SSc $47.6 \%(n=10)$, dSSc $50 \%(n=4)$, kidney - ISSc $9.5 \%(n=2)$, dSSc $0 \%(n$ $=0)$. Fourteen patients with $1 S S c(66 \%)$ and three patients with dSSc (37.5\%) suffered from (systemic) arterial hypertension. Digital ulcers were diagnosed in three patients with 1 SSc $(14.2 \%)$ and in two subjects (25 \%) with dSSc. At the time of inclusion into the study immunomodulatory/immunosuppressive treatment was performed in five patients (cyclophosphamide 1, prednisolone only 2, prednisolone + azathioprine 1 , interferone 1) with limited and in three patients (azathioprine 1, cyclophosphamide 1, cyclosporine A 1) with generalized disease. One patient with dSSc (12.5\%) received Bosentan for treating pulmonary hypertension. Additional file 1: Table S1 summarizes the clinical characteristics.

\section{eEPC numbers and regeneration}

Total numbers of circulating eEPCs (CD133+/Flk-1+ cells) significantly differed between controls and SSc patients: Controls $14.6 \pm 2.9 \%$; SSc all $0.4 \pm 0.1 \%$; $1 S S c$ $\pm 0.40 .1 \%$; dSSc $0.5 \pm 0.3 \%$; the respective $p$-values were: Controls vs. SSc all $p<0.0001$; Controls vs. ISSc $p<0.0001$; Controls vs. dSSc $p=0.04$ (Fig. 1). As opposed to previously published studies in certain rheumatic diseases (RA (Rheumatoid Arthritis), GPA (Granulomatosis with Polyangitis) $(11,22)$ ) eEPC colony numbers were not different between the groups: Controls $21.8 \pm 4.1$; SSc all $20 \pm 3$; 1 SSc $20 \pm 3.6$; dSSc $19.8 \pm 5.6$; the respective $p$-values were: Controls vs. SSc all $p=0.7$; Controls vs. ISSc $p=0.7$; Controls vs. dSSc $p=0.8$ (Fig. 1).

\section{Mesenchymal transdifferentiation of blood-derived eEPC}

Since SSc is characterized by collagen deposition in various types of tissues/organs, we aimed to investigate if phenotypic alterations of blood-derived eEPC possibly accompany the process of localized/generalized fibrosis. Our particular interest focused on the de-novo expression of mesenchymal marker proteins by the cells. Thus, mononuclear blood cells, cultured according to an

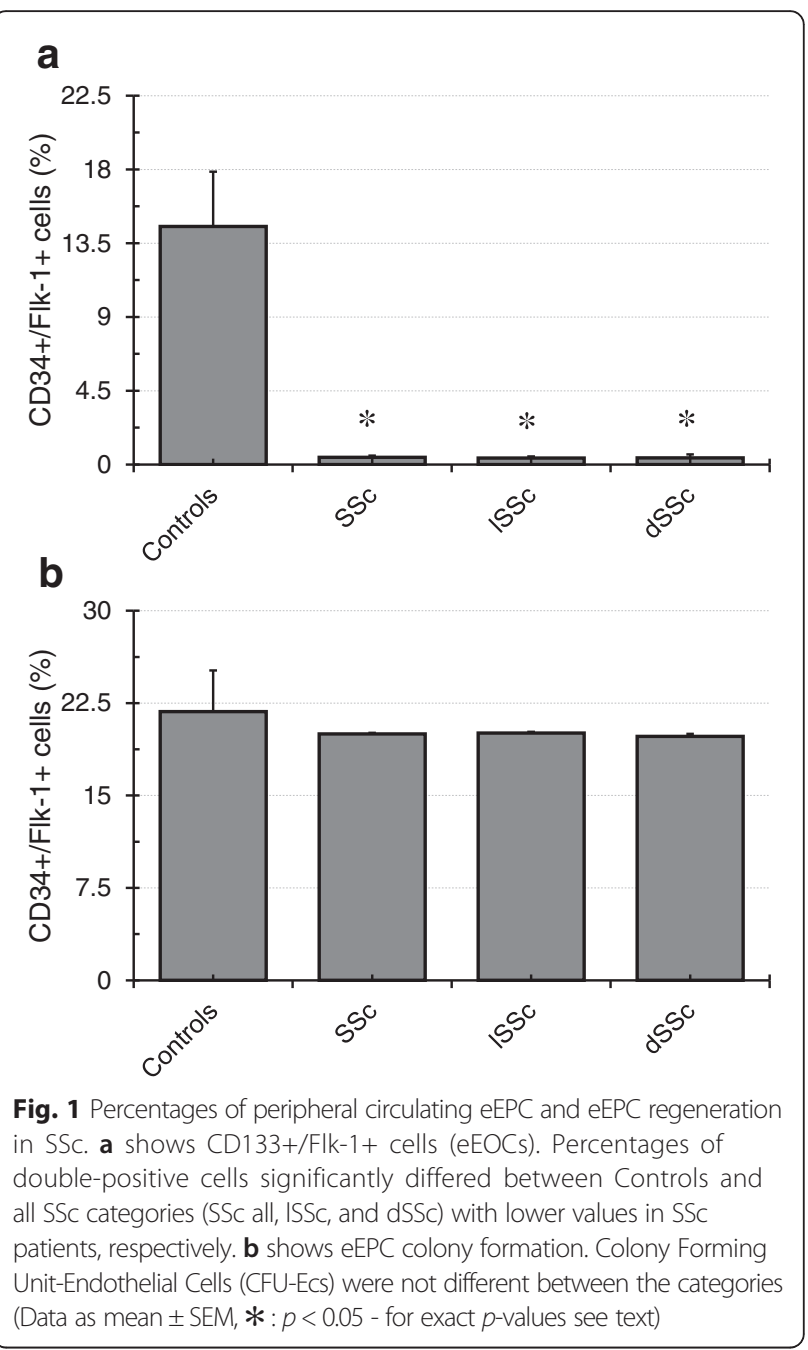

established protocol for eEPC expansion were stained for CD31 and alpha-Smooth Muscle Antigen (aSMA). Patients with SSc (SSc all and ISSc) showed significantly higher percentages of CD31+ cells as compared to healthy controls whereas dSSc patients did not: Controls $72 \pm 12 \%$; SSc all $94 \pm 1.9 \%$; ISSc $95 \pm 1.3 \%$; dSSc $92 \pm$ $4.6 \%$; the $p$-values were: Controls vs. SSc all $p=0.01$; Controls vs. 1SSc $p=0.03$; Controls vs. dSSc $p=0.18$ (Fig. 2). In addition, percentages of CD31+ cells expressing aSMA were also higher in both, SSc all and 1SSc: Controls $65 \pm 13 \%$; SSc all $90 \pm 2.8 \%$; 1SSc $92 \pm 2.1 \%$; dSSc $88 \pm 6.7 \%$; the $p$-values were: Controls vs. SSc all $p=0.01$; Controls vs. 1SSc $p=0.02$; Controls vs. dSSc $p=0.17$ (Fig. 2).

These results were further confirmed by an additional analysis, using the mesenchymal marker FSP-1 (23). Cultured mononuclear cells were stained for UE lectin, acLDL, and FSP-1 and percentages of triple-positive cells were significantly elevated in all patients with SSc (SSc all) and in patients with limited disease (ISSc) (SSc 

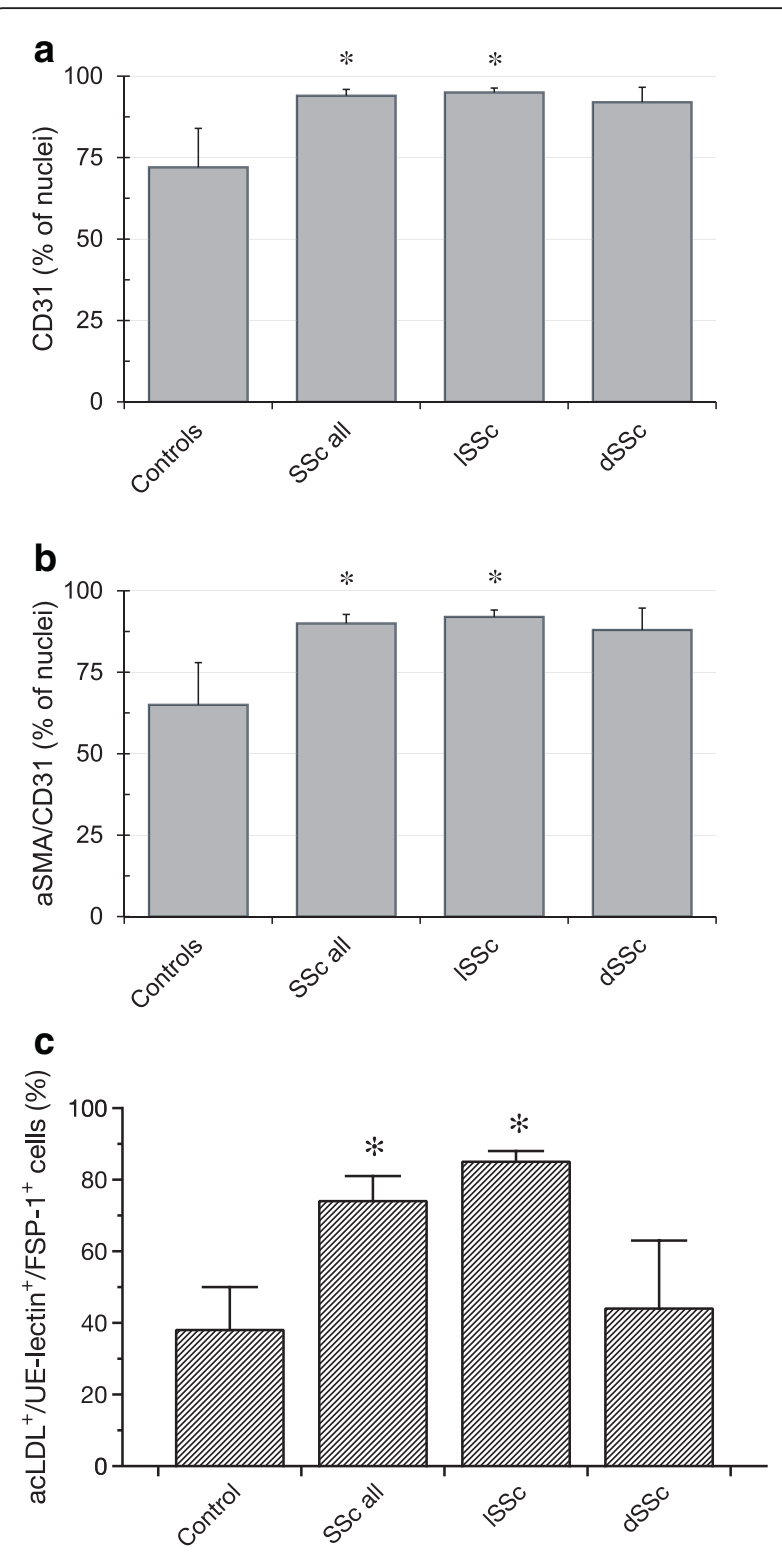

Fig. 2 Mesenchymal transdifferentiation of blood-derived eEPCs in SSC. Expression CD31 was significantly higher in all patients with SSC and in ISSc, dSSC did not differ from Controls (a). b displays aSMA in CD31+ cells with higher percentages in SSC all and in ISSC. $\mathbf{c}$ shows results of additional marker staining (FSP-1), the results were comparable to those aquired with aSMA (Data as mean \pm SEM, $*: p<0.05$ - for exact $p$-values see text)

all $74 \pm 7 \%$ and 1SSc $85 \pm 3 \%$ vs. controls $38 \pm 2 \%$, $p=0.01$ and $p<0.0005$ - Fig. 2).

\section{Angiomodulatory/profibrotic mediators}

Serum concentrations of distinct vasomodulatory and pro-mesenchymal mediators were evaluated since impaired eEPC regeneration has been shown to be associated with defects in the Ang-1/-2 system. In addition, Ang-1/-2 and VEGF are known agonists of eEPCs under certain circumstances and TGF-beta has been identified as potent inductor of fibrogenesis in renal and other diseases [23, 24]. Concentrations of Angiopoietin-1 and -2, Platelet Derived Growth Factor (PDGF), and Vascular Endothelial Growth Factor (VEGF) did not differ between controls and either all patients with SSc, or with $1 \mathrm{SSc} / \mathrm{dSSc}$ (Ang- 1 in pg/ml: Controls $2595 \pm 609$; SSc all $3309 \pm 484$; ISSc $2958 \pm 418 ;$ dSSc $4478 \pm 1530$; all $p$-values $>0.05$; Ang-2 in pg/ml: Controls $1506 \pm 162$; SSc all $1877 \pm 374$; ISSc $1805 \pm 429 ;$ dSSc $2117 \pm 760 ;$ all $p$-values $>0.05$; VEGF in pg/ml: Controls $35 \pm 10.5$; SSc all $58 \pm 12.8$; $1 S S c$ $55 \pm 16$; dSSc $67.5 \pm 14.3$; all $p$-values $>0.05$; PDGF in pg/ $\mathrm{ml}$ : Controls $48.8 \pm 13$; SSc all $77.7 \pm 10.5$; 1 SSc $67.5 \pm 9.6$; dSSc $111.7 \pm 28.7$; all $p$-values $>0.05)$.

Transforming Growth Factor-beta (TGF-b) was significantly higher in all patients with SSc as compared to the Controls (TGF-b in pg/ml: Controls $4549 \pm 677$; SSc all $6259 \pm 495$; 1 SSc $6057 \pm 533$; dSSc $6935 \pm 1246$; $p$-value for Controls vs. SSc all 0.049) (Fig. 3).

\section{Serum-induced eEPC migration and mesenchymal transdifferentiation}

Finally, serum samples from healthy subjects and SSc patients were used for incubating cultured human eEPCs, followed by analysis of cell migration and mesenchymal transdifferentiation. Five hours after wound induction migration of eEPC, treated with serum from SSc patients was significantly slower as compared to those incubated with serum from healthy subjects (wound area reduction in \%: healthy subjects $60 \pm 2.9$; SSc patients $38 \pm 1.7 ; p<0.0001)$. Simultaneous Bosentan administration to the culture medium reduced migration in the 'healthy subject' but not in the 'SSc' category (wound area reduction in \%: healthy subjects $49 \pm 3.5$; SSc patients $35 \pm 2.5$; p for healthy subjects with versus without Bosentan administration 0.03). These effects exclusively occurred under the following conditions: serum:medium-ratio 1:5, Bosentan concentration $2000 \mathrm{ng} / \mathrm{ml}$.

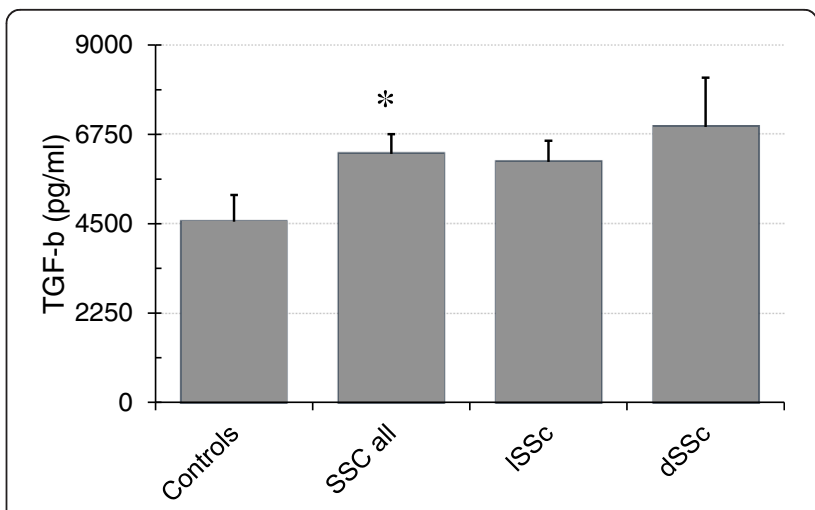

Fig. 3 Pro-mesenchymal TGF-b in SSc. All Patients with SSc (SSc all) showed higher concentrations of TGF-b as compared to healthy controls (Data as mean \pm SEM, $*$ : $p<0.05$ - for exact $p$-values see text) 
Two further experimental settings were evaluated: serum:medium-ratio 1:7.5 with Bosentan $2000 \mathrm{ng} / \mathrm{ml}$ or $1000 \mathrm{ng} / \mathrm{ml}$. However, although cells treated with serum from healthy controls tended to migrate faster in all groups, the differences as compared to SSc patients were not statistically significant. Figure 4 summarizes the results. Analysis of mesenchymal transdifferentiation of the cells revealed comparable levels of aSMA expression by the cells in healthy subjects and SSc patients with or without Bosentan treatment (eEPCs stained positive for aSMA in \%: healthy subjects - no Bosentan $42 \pm 8$ and $33 \pm 5$ with Bosentan; SSc patients, no Bosentan $29 \pm 7$ and $33 \pm 6$ with Bosentan - Fig. 4). The differences were not statistically significant between any of the respective categories.

\section{Discussion}

The two fundamental results of the current study were (I) the lower percentages of circulating eEPC all analyzed categories (SSc all, ISSc, dSSc) and (II) the promesenchymal switch of cultured blood-derived eEPCs in SSc in general and in ISSc in particular. Another interesting finding was related to reduced migratory activity of cultured eEPCs in the presence of serum from SSc patients

The life-threatening nature of systemic sclerosis results from two pathological phenomenona: limited or generalized fibrosis and vascular obstruction/occlusion [25]. The latter is critically mediated by endothelial cell proliferation with subsequent intimal hyperplasia [26]. The mechanisms responsible for endothelial expansion

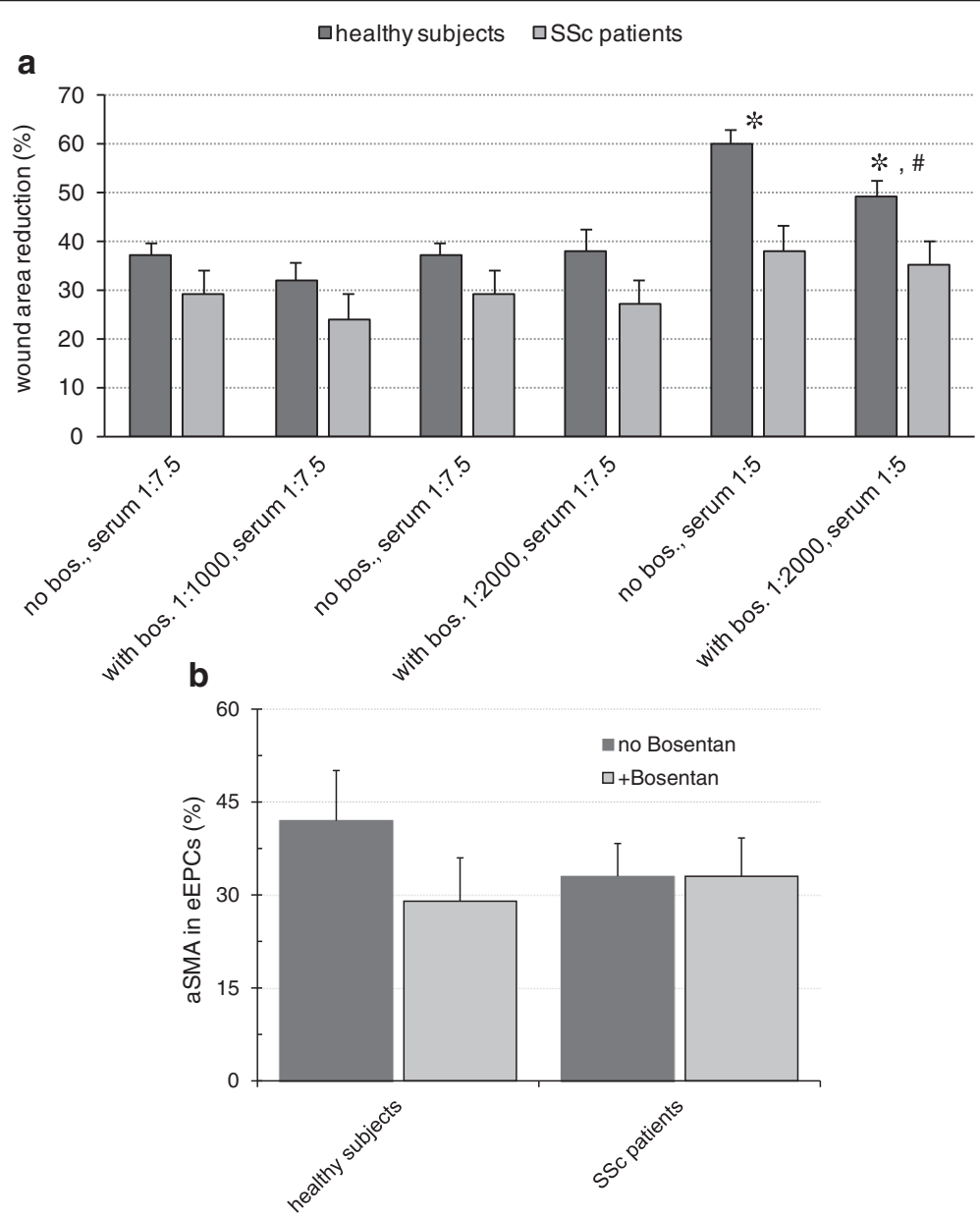

Fig. 4 eEPC migration and EndoMT in vitro. Cultured human eEPCs were treated with serum samples from healthy controls, and from patients with SSC with versus without simultaneous administration of Bosentan to the culture medium. Analysis were performed at $5 \mathrm{~h}$ after beginning of the incubation. In general, migration of eEPC treated with patient serum was significantly slower (a). Bosentan reduced cellular migration in the 'healthy subjects' category. This effect exclusively occurred under the following experimental conditions: serum:medium-ratio 1:5, Bosentan concentration $2000 \mathrm{ng} / \mathrm{ml}$. Expression of aSMA by the cells was comparable in all categories with no significant alteration by Bosentan (b - experimental conditions: serum:medium-ratio 1:5, Bosentan concentration $2000 \mathrm{ng} / \mathrm{ml}$ ) (bos.: Bosentan; 'serum' represents the serum:medium-ratio; Data as mean \pm SEM, *: differences between healthy subjects and SSc patients within a group significant with $p<0.05$; \#: differences between healthy subjects between two groups significant with with $p<0.05)$ 
have been studied in recent years but the current knowledge is still very limited. Among the factors that have been suggested to contribute to endothelial proliferation/functional transformation were chemical substances, vasculotropic viral pathogens, anti-endothelial cell autoantibodies, and others [2, 26-32]. In this context it has to be recognized that the endothelium does not only increasingly proliferate but also (most likely) undergoes a process of mesenchymal transdifferentiation or Endothelial-to-Mesenchymal Transition (EndoMT) [25]. In other situations, EndoMT has been documented to perpetuate cardiac and renal fibrosis [33-35]. SSc-related fibrogenesis significantly results from interstitial accumulation of myofibroblasts and these cells are being discussed to, at least in part originate from the vascular endothelium [25]. The microenvironmental humoral milieu is substantially affected in SSc. In a more recent study Guiducci and colleagues showed SScderived Mesenchymal Stem Cells (MSCs) to release numerous bioactive/proangiogenic factors that potentially stimulate angiogenesis and fibrosis (SDF-1, VEGF, TGFbeta) [36]. Such alterations, which are partly reflected by increases of circulating pro-mesenchymal substances (TGF-b - see results) may promote endothelial transdifferentiation into cells with mesenchymal properties. Several studies showed a critical role for Transforming Growth Factor-beta in mediating EndoMT [23, 35]. Early Endothelial Progenitor Cells have been documented to stabilize the microvasculature mostly by indirect mechanisms including the release of vasomodulatory mediators in close proximity to the endothelium [17]. Thus, eEPCs maintain the integrity of blood vessels under both, physiological and pathological conditions. The increased expression of mesenchymal proteins by the cells in SSc (SSc all and ISSc) has two possible implications. Firstly, it potentially reflects the inability of the cells to stabilize the endothelial 'identity' in a way that EndoMT ensues. Secondly, it is not a hallmark of functional eEPC incompetence but an attendant phenomenon of the complex humoral and cellular events that occur during the process leading to SS-associated fibrosis and vasculopathy. Regarding EndoMT, it can only be speculated whether dSSc patients did not show significantly higher percentages of CD31+/aSMA+ and acLDL+/BS-1+/FSP-1+ cells as compared to the Controls. In general, $\mathrm{dSSc}$ is associated with more severe end organ damage including more aggravated fibrosis and often higher risk and prevalence of digital ulcers. It somehow surprises that in comparison to controls, the two mentioned cell populations were not higher in dSSc. However, in the latter group immunosuppressive treatment was performed in $37.5 \%$ as opposed to $23.3 \%$ in the 1SSc group. Low-dose chemotherapy for instance has been shown to reduce EPC mobilization into the blood of cancer patients [37]. Thus, the lack of differences between controls and dSSC may potentially also result from therapy-associated effects.

Another interesting result of our study was related to circulating eEPCs and to eEPC regeneration. CFU-ECs have been evaluated in several own studies, with altered colony formation in all investigations published so far $[11,13,18,19,22]$. The current study did not reveal impaired eEPC regeneration but a significant lack of circulating cells in all categories. One may argue that SSc is characterized by increased eEPC turnover, due to generalized microvascular damage and repair. In this respect, the normal colony numbers may reflect stimulated regeneration as well which nevertheless is not sufficient to compensate peripheral cell degradation. Nevertheless, to draw any definite conclusions is surely too early yet. At this point it has to be realized that other studies related to EPCs in SSc showed results, seemingly conflicting with our data. Allanore and colleagues found increased levels of CD34+/CD133+ cells in SSc as compared to osteoarthritis patients [14]. Firstly, it still can be argued whether CD34+/CD133+ cells truly represent circulating eEPCs, whose proliferative potential was investigated by us. Fadini et al. discussed the origin and phenotype of different EPC subtypes in a very detailed manner [17] and it can be doubted that the cells cultured in our study exclusively arise from CD34+/CD133+ cells. In addition, several own investigations showed that eEPC regeneration and numbers of circulating CD133+/KDR + cells do not necessarily correlate in a positive manner $[11,13,19]$.

Serum from SSc patients significantly reduced eEPC migration, a phenomenon which remained unaffected by Bosentan administration. After being incubated with serum from healthy Controls however cell migration was inhibited, potentially indicating that the cells were at least capable of interacting with the substance. Thus, serum from SSc patients may have reduced the cellular response to Bosentan which possibly indicates some degree of functional cell incompetence or Endothelial (Progenitor Cell) Dysfunction (ED) (37). In the past, anti-endothelin therapy has successfully been used in SSc with digital vasculopathy $[38,39]$ and endothelin has also been suggested to mechanistically contribute to the progression of SSc-associated fibrosis [40].

We would finally like to shortly discuss some limitations of the current study. In general, monitoring mesenchymal properties of circulating cells such as eEPCs allows to conclude about microvascular abnormalities only in an approximative manner. Secondly, the de-novo appearance of mesenchymal characteristics in eEPCs may potentially occur as bystander phenomenon within a systemic 'pro-mesenchymal' milieu. Thus, any eEPC 'responsibility' for aggravated skin and end-organ fibrosis may not be assumed. Finally, eEPCs represent only one 
of two EPC subpopulations. Investigations performed in recent years indicate that late EPCs (IEPCs) most likely are true progenitors of the endothelium whereas eEPCs support endothelial regeneration by indirect mechanisms [41]. Therefore, further studies should also address the role of the latter in SSc-associated fibrosis and microvasculopathy.

\section{Conclusions}

In summary, the eEPC system, which represents an essential element in the endogenous vascular repair machinery is severely affected in SSc. The increased appearance of mesenchymal properties in eEPC may indicate that alterations of the cells contribute to or at least perpetuate the accumulation of connective tissue and the vascular malfunction.

\section{Additional file}

Additional file 1: Table S1. Summarizes the baseline characteristics of all patients (see text for further details). (PDF $28 \mathrm{~kb}$ )

\begin{abstract}
Abbreviations
ACR, American College of Rheumatology; aSMA, alpha Smooth Muscle Actin; CT, computed tomography; Dil-acLDL, Dil-labelled acetylated low density lipoprotein; dSSc, diffuse (generalized) systemic sclerosis; eEPCs, early endothelial progenitor cells; EULAR, European League Against Rheumatism; FSP-1, fibroblast specific protein-1; GPA, granulomatosis with polyangitis; ISSC, limited systemic sclerosis; PDGF, platelet derived growth factor; RA, rheumatoid arthritis; SSc, systemic sclerosis; TGF-b, transforming growth factor-beta; UE lectin, Ulex Europaeus lectin; VEGF, vascular endothelial growth factor
\end{abstract}

\section{Acknowledgements}

Not applicable.

\section{Funding}

The studies were supported by the Heidenreich von-Siebold Programm.

\section{Availability of data and materials}

All the data supporting our findings is contained within the manuscript.

\section{Authors' contributions}

SP designed the study and recruited patients. DT performed cell culture experiments. CM performed cytometric analyses. CS recruited patients. $\mathrm{CH}$ recruited patients. GAM corrected the manuscript. EZ performed cell culture experiments and analyzed data. MZ analyzed data and assisted in writing the manuscript. EH performed cell culture experiments. DP analyzed data and wrote the manuscript. All authors read and approved the final manuscript.

\section{Competing interest}

The authors declare that they have no competing interests.

\section{Ethics approval and consent to participate}

The study was formally approved by the local ethics committee (official name: Ethics Committee of the Georg-August-Universität Göttingen). All patients signed written consent.

\section{Consent for publication}

Not applicable.

\section{Author details}

'Clinic of Nephrology and Rheumatology, University Hospital of Göttingen, Robert-Koch-Straße 40, 37075 Göttingen, Germany. ${ }^{2}$ Clinic of Dermatology, University Hospital of Göttingen, Robert-Koch-Straße 40, 37075 Göttingen, Germany.
Received: 12 February 2016 Accepted: 30 July 2016

Published online: 12 August 2016

\section{References}

1. Goldblatt F, O'Neill SG. Clinical aspects of autoimmune rheumatic diseases. Lancet Lond Engl. 2013;382:797-808.

2. Matucci-Cerinic M, Kahaleh B, Wigley FM. Review: evidence that systemic sclerosis is a vascular disease. Arthritis Rheum. 2013;65:1953-62.

3. Mowat A. Connective tissue diseases. Clin Haematol. 1972;1:573-94.

4. Manno R, Boin F. Immunotherapy of systemic sclerosis. Immunotherapy. 2010;2:863-78.

5. Asahara T, Murohara T, Sullivan A, Silver M, van der Zee R, Li T, et al. Isolation of putative progenitor endothelial cells for angiogenesis. Science. 1997;275:964-7.

6. Case J, Mead LE, Bessler WK, Prater D, White HA, Saadatzadeh MR, et al. Human CD34 + AC133 + VEGFR-2+ cells are not endothelial progenitor cells but distinct, primitive hematopoietic progenitors. Exp Hematol. 2007;35: 1109-18.

7. Yoder MC, Mead LE, Prater D, Krier TR, Mroueh KN, Li F, et al. Redefining endothelial progenitor cells via clonal analysis and hematopoietic stem/ progenitor cell principals. Blood. 2007;109:1801-9.

8. Basile DP, Yoder MC. Renal endothelial dysfunction in acute kidney ischemia reperfusion injury. Cardiovasc Hematol Disord Drug Targets. 2014;14:3-14.

9. Chen J, Chen J, Chen S, Zhang C, Zhang L, Xiao X, et al. Transfusion of CXCR4-primed endothelial progenitor cells reduces cerebral ischemic damage and promotes repair in db/db diabetic mice. PLoS One. 2012;7, e50105.

10. Martí-Fàbregas J, Crespo J, Delgado-Mederos R, Martínez-Ramírez S, Peña E, Marín $R$, et al. Endothelial progenitor cells in acute ischemic stroke. Brain Behav. 2013:3:649-55.

11. Patschan S, Patschan D, Henze E, Blaschke S, Wessels JT, Müller G-A. Impairment and differential expression of PR3 and MPO on peripheral myelomonocytic cells with endothelial properties in granulomatosis with polyangiitis. Int J Nephrol. 2012;2012:715049-12.

12. Zhao YH, Yuan B, Chen J, Feng DH, Zhao B, Qin C, et al. Endothelial progenitor cells: therapeutic perspective for ischemic stroke. CNS Neurosc Ther. 2013;19:67-75.

13. Patschan SA, Patschan D, Temme J, Korsten P, Wessels JT, Koziolek M, et al. Endothelial progenitor cells (EPC) in sepsis with acute renal dysfunction (ARD). Crit Care Lond Engl. 2011;15:R94.

14. Allanore Y, Batteux F, Avouac J, Assous N, Weill B, Kahan A. Levels of circulating endothelial progenitor cells in systemic sclerosis. Clin Exp Rheumatol. 2007:25:60-6

15. Del Papa N, Quirici N, Soligo D, Scavullo C, Cortiana M, Borsotti C, et al. Bone marrow endothelial progenitors are defective in systemic sclerosis. Arthritis Rheum. 2006;54:2605-15.

16. Distler JHW, Allanore Y, Avouac J, Giacomelli R, Guiducci S, Moritz F, et al. EULAR scleroderma trials and research group statement and recommendations on endothelial precursor cells. Ann Rheum Dis. 2009;68:163-8.

17. Fadini GP, Losordo D, Dimmeler S. Critical reevaluation of endothelia progenitor cell phenotypes for therapeutic and diagnostic use. Circ Res. 2012;110:624-37.

18. Patschan D, Patschan S, Henze E, Wessels JT, Koziolek M, Müller GA. LDL lipid apheresis rapidly increases peripheral endothelial progenitor cell competence. J Clin Apheresis. 2009;24:180-5.

19. Patschan S, Patschan D, Potulski M, Henze E, Scholze J, Müller G-A. Endothelial progenitor cells in systemic lupus erythematosus. J Nephrol. 2013;26:1065-72.

20. van den Hoogen F, Khanna D, Fransen J, Johnson SR, Baron M, Tyndall A, et al. 2013 classification criteria for systemic sclerosis: an American College of Rheumatology/European League against Rheumatism collaborative initiative. Arthritis Rheum. 2013;65:2737-47.

21. LeRoy EC, Medsger TA. Criteria for the classification of early systemic sclerosis. J Rheumatol. 2001;28:1573-6.

22. Patschan S, Nemirovsky K, Henze E, Scholze J, Müller GA, Patschan D. Tocilizumab increases EPC regeneration in rheumatoid arthritis. Scand J Rheumatol. 2014;43:528-30.

23. Xavier S, Vasko R, Matsumoto K, Zullo JA, Chen R, Maizel J, et al. Curtailing endothelial TGF- $\beta$ signaling is sufficient to reduce endothelial-mesenchymal transition and fibrosis in CKD. J Am Soc Nephrol JASN. 2015;26:817-29. 
24. Zeisberg M, Hanai J, Sugimoto H, Mammoto T, Charytan D, Strutz F, et al. BMP-7 counteracts TGF-beta1-induced epithelial-to-mesenchymal transition and reverses chronic renal injury. Nat Med. 2003;9:964-8.

25. Jimenez SA. Role of endothelial to mesenchymal transition in the pathogenesis of the vascular alterations in systemic sclerosis. ISRN Rheumatol. 2013;2013:835948.

26. Abraham D, Distler O. How does endothelial cell injury start? The role of endothelin in systemic sclerosis. Arthritis Res Ther. 2007;9 Suppl 2:S2.

27. Kahaleh B. Vascular disease in scleroderma: mechanisms of vascular injury Rheum Dis Clin North Am. 2008;34:57-71. vi.

28. Müller-Ladner U, Distler O, Ibba-Manneschi L, Neumann E, Gay S. Mechanisms of vascular damage in systemic sclerosis. Autoimmunity. 2009;42:587-95.

29. Neidhart M, Kuchen S, Distler O, Brühlmann P, Michel BA, Gay RE, et al. Increased serum levels of antibodies against human cytomegalovirus and prevalence of autoantibodies in systemic sclerosis. Arthritis Rheum. 1999;42: 389-92.

30. Pandey JP, LeRoy EC. Human cytomegalovirus and the vasculopathies of autoimmune diseases (especially scleroderma), allograft rejection, and coronary restenosis. Arthritis Rheum. 1998;41:10-5.

31. Renaudineau Y, Grunebaum E, Krause I, Praprotnik S, Revelen R, Youinou P. et al. Anti-endothelial cell antibodies (AECA) in systemic sclerosis-increased sensitivity using different endothelial cell substrates and association with other autoantibodies. Autoimmunity. 2001;33:171-9.

32. Trojanowska M. Cellular and molecular aspects of vascular dysfunction in systemic sclerosis. Nat Rev Rheumatol. 2010;6:453-60.

33. O'Riordan E, Mendelev N, Patschan S, Patschan D, Eskander J, Cohen-Gould $L$, et al. Chronic NOS inhibition actuates endothelial-mesenchymal transformation. Am J Physiol Heart Circ Physiol. 2007;292:H285-94.

34. Zeisberg EM, Tarnavski O, Zeisberg M, Dorfman AL, McMullen JR, Gustafsson E, et al. Endothelial-to-mesenchymal transition contributes to cardiac fibrosis. Nat Med. 2007;13:952-61.

35. Zeisberg EM, Potenta SE, Sugimoto H, Zeisberg M, Kalluri R. Fibroblasts in kidney fibrosis emerge via endothelial-to-mesenchymal transition. J Am Soc Nephrol JASN. 2008;19:2282-7.

36. Guiducci S, Manetti M, Romano E, Mazzanti B, Ceccarelli C, Dal Pozzo S, et al. Bone marrow-derived mesenchymal stem cells from early diffuse systemic sclerosis exhibit a paracrine machinery and stimulate angiogenesis in vitro. Ann Rheum Dis. 2011;70:2011-21.

37. Stoelting S, Trefzer T, Kisro J, Steinke A, Wagner T, Peters SO. Low-dose oral metronomic chemotherapy prevents mobilization of endothelial progenitor cells into the blood of cancer patients. Vivo Athens Greece. 2008;22:831-6.

38. Cutolo M, Ruaro B, Pizzorni C, Ravera F, Smith V, Zampogna G, et al. Longterm treatment with endothelin receptor antagonist bosentan and iloprost improves fingertip blood perfusion in systemic sclerosis. J Rheumatol. 2014:41:881-6.

39. Parisi S, Bruzzone M, Centanaro Di Vittorio C, Laganà A, Peroni CL, Fusaro E. Efficacy of bosentan in the treatment of Raynaud's phenomenon in patients with systemic sclerosis never treated with prostanoids. Reumatismo. 2013; 65:286-91.

40. Kill A, Tabeling C, Undeutsch R, Kühl AA, Günther J, Radic M, et al. Autoantibodies to angiotensin and endothelin receptors in systemic sclerosis induce cellular and systemic events associated with disease pathogenesis. Arthritis Res Ther. 2014;16:R29.

41. Patschan D, Schwarze K, Henze E, Patschan S, Müller GA. Am J Physiol Renal Physiol. 2016 Jan 20:ajprenal.00306.2015. doi:10.1152/ajprenal.00306.2015. [Epub ahead of print].

\section{Submit your next manuscript to BioMed Central and we will help you at every step:}

- We accept pre-submission inquiries

- Our selector tool helps you to find the most relevant journal

- We provide round the clock customer support

- Convenient online submission

- Thorough peer review

- Inclusion in PubMed and all major indexing services

- Maximum visibility for your research

Submit your manuscript at www.biomedcentral.com/submit
Biomed Central 